\title{
Your Invitation to a New Partnership in Discovery and Invention
}

\author{
Norman E. Taylor*
}

Science has been described as a systematic enterprise that uses various forms of measurement to create, build and organize knowledge in the form of verifiable observations, explanations and predictions about the world around us ${ }^{1}$. Social science is the branch of that enterprise that deals with the institutions and functioning of human society, and with the interpersonal relationships of the individuals, families and communities that comprise that society ${ }^{2}$. Some have noted that such an enterprise requires equal parts discovery and invention. We may discover that society generally acts in ways that are regular and predictable enough to be defined. But, we must also invent the experimental techniques, research methods and organization for testing, exhibiting, and ultimately applying what we learn ${ }^{3}$. In effect, we must invent the means to travel from research, to practice, to the ultimate alignment of the systems that are intended to serve that society. The Journal of Community Safety and Well Being is one such invention. And, this Journal emerges into a time of important and necessary discovery.

Over two decades ago, Peter Senge observed in The Fifth Discipline ${ }^{4}$, his seminal work on systems theory, that the most intractable of learning disabilities in any human system often manifest most vividly among those who have served the longest tenure and made the greatest achievements within it. Thus, it follows that a great many of the structures and public institutions that shape our current health, social, education, child welfare, policing, and criminal justice sectors each stand tall, steadfastly separate - and most typically acting apart - as pillars of achievement in industrial era bureaucracy. One has to wonder if the late George Odiorne had known what might come about, perhaps he may have reconsidered championing the 1960's movement in the highly engineered concepts of management-by-objectives ${ }^{5}$. Dominated ever since by a system where the accountability and career rewards of individuals and managers have favoured strict adherence to easily defined and measurable outputs, often at the expense of displacing and eroding the fundamental mission of their agency, it is little surprise that we are all now facing the harsh consequences from decades of collectively and systematically losing the plot.

We have erected high functioning silos, but we are discovering that they are much too expensive to sustain. We built them to serve the many complex needs of a post-modern world, many of them dedicated to serving the most vulnerable, the marginalized, the victimized, and often the more troubled members of our society. But, with the utmost respect to the professionals who do the now necessary work of guiding the lost and confused clients of our services, can we really take pride in the fact that one of the more popular job titles to emerge in recent years is that of the system navigator, among many similar variations on that same theme (e.g., clinical navigator, patient navigator, community navigator, health care navigator, nurse navigator) ${ }^{6}$ ?

Now, more than ever before as our $21^{\text {st }}$ century social and economic reality continues to widen many gaps, we desperately need to regain the essential storyline. Our publicly funded human services exist to serve the needs of individuals, families, and communities - none of whom is inclined to package their needs conveniently enough to match the many doors through which the most necessary assistance might be found. We must realign the system. We must discover new ways to meet and serve those needs where and as they are. And, most importantly, we must recognize, understand, and serve those needs early enough that we can shape better lives, build stronger families, and ensure that our children can achieve their full potential in safe and healthy communities.

Responding to crisis in its many diverse forms may be what a fragmented system does best. But, such responses are almost always the most expensive option, and tragically, they almost always offer the most limited outcomes. Conversely and optimistically (as our own upcoming inaugural issue will attest), we are facing a growing body of evidence that 'silo' approaches can indeed yield to collaborative modes of operation; that early intervention can bring redirection and lasting support to troubled lives; that information must be shared; that our massive social data sets can be mined, effectively and responsibly, for their predictive value; that understanding victimization is at least as important as understanding crime; and that working across disciplines to improve outcomes can reduce the demand for complex services. Taken collectively, we are learning that embracing community safety and well being, together, may offer the only viable path toward the economic sustainability of our costly public services.

Correspondence to: Norman Taylor, Editor-in-Chief, Journal of Community Safety and Well-Being (CSWB), 111 Research Drive, Suite \#105, Saskatoon, Saskatchewan S7N 3R2. E-mail: ntaylor@cskacanada.ca 
Canada is not alone in confronting the challenges of retooling its public service toward more collaborative, preventive, and comprehensive approaches to meeting social needs. As such, we stand to both contribute and gain from wider participation in global efforts to advance new solutions, and to back up those solutions with genuine knowledge, proven practices, and relevant social science research. Similarly, the widely recognized social innovations and collaborative models in CSWB that have emerged from Saskatchewan since 2010 are certainly not the only Canadian examples of highly promising policy and practice. But, they have done a lot to stimulate interest, raise awareness, and amplify the necessary conversation. Since 2013, nowhere has this conversation grown louder than in the province of Ontario. And today, aggressive efforts at reforming the system towards upstream, multi-sector, risk-based and data-driven solutions are emerging from almost every province and territory.

The Community Safety Knowledge Alliance (CSKA) was formed last year, thus initiating a growing, multi-partner, and an increasingly global commitment to generating and advancing reliable social science knowledge in support of this CSWB movement. CSKA recognizes that, like all innovations before, even the growing chorus of voices behind these collaborative risk-driven models will remain at a considerable disadvantage to the Goliath of established practice and deeply entrenched organizational culture. Without a credible base of evidence, even the most promising innovations in any field of endeavor face high risk of early extinction. And, establishing such credibility across the multiple human service and justice disciplines that contribute to CSWB may be an unprecedented ambition.

This peer-reviewed Journal is a flagship initiative of, and an essential companion to, the CSKA mission of taking research to practice to alignment ${ }^{7}$. Together with our highly distinguished and multi-disciplinary Editorial Board, we are currently preparing to launch our inaugural issue in August of this year. With strong contributions from a diverse mix of authors, and with the help of our experienced publishing partner Multimed Inc., our first online, open access issue is already shaping up to signal clearly the arrival of a new and rich environment for sharing and promoting timely research, experimentation, and dialogue. The Journal of CSWB will provide an open channel for academics and practitioners alike to advance social innovation and showcase promising practices, and it aims to engage professionals and executives in every CSWB sector in a continuing partnership with our contributing authors. Together, we can discover and invent, and with the clarity of social science to guide us, we might just change the way we all do business.

I am honoured to serve as the Editor-in-Chief for this Journal, and I am thrilled to be the first to invite you into this partnership.

\section{CONFLICT OF INTEREST DISCLOSURES}

I have read and understood Journal of Community Safety and WellBeing's policy on disclosing conflicts of interest, and I declare that I have none.

\section{AUTHOR AFFILIATIONS}

*Journal of Community Safety and Well-Being (CSWB), Saskatoon, SK.

\section{REFERENCES}

1. Wilson, Edward (1999). Consilience: The unity of knowledge. New York: Vintage.

2. Merriam-Webster Dictionary (2016). Social science definition Retrieved April 27, 2016 from http://www.merriam-webster.com/ dictionary/social\%20science

3. Heilbron, J. L. (2003). The Oxford companion to the history of modern science. (p. vii.) New York: Oxford University Press.

4. Senge, Peter M. (1990). The fifth discipline. The art \& practice of the learning organization. New York: Doubleday/Currency.

5. Lambert, Bruce (1992). George S. Odiorne is dead at 71: Developed theory of management [obituary]. The New York Times. Retrieved April 27, 2016 from http://www.nytimes.com/1992/01/23/ obituaries/george-s-odiorne-is-dead-at-71-developed-theory-ofmanagement.html

6. Yahoo (2016). System navigator job title. Retrieved April 27, 2016 from https://search.yahoo.com/search? ei=utf-8\&fr=aaplw\&p= system+navigator+job+title

7. CSKA (2015). Community safety knowledge alliance [website Home page]. Retrieved April 27, 2016 from www.cskacanada.ca 